\title{
Snacking between main meals is associated with a higher risk of metabolic syndrome in a Mediterranean cohort: the SUN Project (Seguimiento Universidad de Navarra)
}

\author{
Adriano M Pimenta ${ }^{1,2, *}$, Maira Bes-Rastrollo ${ }^{1,3}$, Alfredo Gea ${ }^{1}$, Carmen Sayón-Orea ${ }^{1}$, \\ Itziar Zazpe ${ }^{1,3,4}$, Roberto Lopez-Iracheta ${ }^{1}$ and Miguel A Martinez-Gonzalez ${ }^{1,3}$ \\ 'Department of Preventive Medicine and Public Health, School of Medicine, University of Navarra, Pamplona, \\ Spain: ${ }^{2}$ Department of Maternal-Child Nursing and Public Health, School of Nursing, Universidade Federal de Minas \\ Gerais, Av. Prof. Alfredo Balena 190, Belo Horizonte, Minas Gerais, CEP 30130-100, Brazil: ${ }^{3}$ CIBER Fisiopatología \\ de la Obesidad y Nutrición (CIBERobn), Instituto de Salud Carlos III, Madrid, Spain: ${ }^{4}$ Department of Nutrition and \\ Food Sciences and Physiology, University of Navarra, Navarra, Spain
}

Submitted 16 May 2014: Final revision received 19 November 2014: Accepted 6 March 2015: First published online 11 May 2015

\begin{abstract}
Objective: To evaluate the association of snacking between main meals with the risk of developing metabolic syndrome.

Design: A dynamic prospective cohort study (the SUN Project; Seguimiento Universidad de Navarra). Snack consumption was evaluated using the question: 'Do you have the habit of snacking between main meals?' Metabolic syndrome was defined according to the updated harmonizing criteria. We estimated multivariable-adjusted relative risks (RR) of metabolic syndrome and their $95 \%$ confidence intervals using Poisson regression models. An exploratory factor analysis was also used to identify patterns of snacking.

Setting: University of Navarra, Spain.

Subjects: The study included 6851 university graduates, initially free of metabolic syndrome, and followed-up them for a median of $8 \cdot 3$ years.

Results: Among our participants, 34.6\% reported usual snacking between main meals. The cumulative incidence of metabolic syndrome was 5.1\% (9.5\% among men and $2 \cdot 8 \%$ among women). Snacking between main meals was significantly associated with higher risk for developing metabolic syndrome after multivariable adjustment $(\mathrm{RR}=1.44 ; 95 \% \mathrm{CI} 1.18,1.77)$. Higher adherence to an 'unhealthy snacking pattern' was also independently associated with increased incidence of metabolic syndrome (fourth quartile of adherence compared with non-snacking: $\mathrm{RR}=1 \cdot 68 ; 95 \%$ CI $1 \cdot 23,2 \cdot 29 ; P$ for trend $<0 \cdot 001)$.

Conclusions: Our findings suggest that avoidance of snacking between main meals can be included among the preventive approaches to reduce the risk of metabolic syndrome development, especially when snacks contain foods of poor nutritional quality.
\end{abstract}

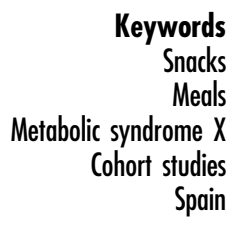

Metabolic syndrome (MetS) is characterized by the clustering of abdominal obesity, dyslipidaemia, hyperinsulinaemia, impaired fasting glucose and high blood pressure, and its prevalence is over $20 \%$ in adult populations around the world ${ }^{(1-3)}$. Besides its high prevalence, MetS is strongly associated with non-communicable diseases, such as type 2 diabetes and CVD, which are among the main public health concerns worldwide ${ }^{(4)}$. Therefore, investigation of the factors potentially associated with the development of MetS is fundamental for the primary prevention of type 2 diabetes and CVD. In this context, unhealthy eating habits are considered to be modifiable determinants of MetS ${ }^{(5,6)}$. Snack consumption has recently been highlighted as one of these potential unhealthy eating habits ${ }^{(7-9)}$. The frequency of snack consumption is relatively high, especially among populations from Western countries ${ }^{(10)}$.

Although there are some studies that have shown an association between snacking and obesity ${ }^{(7,10-12)}$, the relationship of this eating habit with MetS is not well established. To the best of our knowledge, only three cross-sectional studies and one longitudinal study have explored this hypothesis so far. Their findings are inconsistent. The longitudinal study was conducted with 
1466 adults in Tehran (Iran) and reported that higher consumption of energy-dense snacks was associated with an elevated risk of MetS after 3 years of follow-up ${ }^{(13)}$. Similar results were observed in a cross-sectional study conducted among 5682 adults in Australia, where snack consumption was independently associated with a higher prevalence of MetS and its components in women ${ }^{(14)}$. On the other hand, no relationship was found between snack consumption and MetS in the two other cross-sectional studies ${ }^{(15,16)}$.

Thus, we aimed to longitudinally evaluate the association of snacking between main meals with the risk of MetS in large Mediterranean cohort with a prolonged follow-up.

\section{Methods}

\section{Design}

The SUN Project (Seguimiento Universidad de Navarra; University of Navarra Follow-up) is a dynamic prospective cohort study with permanently open recruitment, conducted in Spain among university graduates since December 1999. Additional details on its objectives, design and methods have been previously published elsewhere ${ }^{(17,18)}$.

Information is gathered by mailed or emailed questionnaires collected biennially. After baseline assessment (Q_0), participants received a follow-up questionnaire every 2 years to evaluate changes in lifestyle and healthrelated behaviours, anthropometric measures, incident diseases and medical conditions.

\section{Participants}

The present study was conducted in June 2013, and to warrant a minimum follow-up of 6 years, all participants who had answered their first questionnaire before October 2006 and were free of any MetS-specific definition criterion or diabetes at baseline were considered eligible ( $n$ 11950). Out of this sample, we excluded individuals reporting extremely low or high total energy intake values $(<3347 \mathrm{~kJ} / \mathrm{d}(<800 \mathrm{kcal} / \mathrm{d})$ in men and $<2092 \mathrm{~kJ} / \mathrm{d}(<500$ $\mathrm{kcal} / \mathrm{d})$ in women; $>16736 \mathrm{~kJ} / \mathrm{d}(>4000 \mathrm{kcal} / \mathrm{d})$ in men and $>14644 \mathrm{~kJ} / \mathrm{d} \quad(>3500 \mathrm{kcal} / \mathrm{d})$ in women $)^{(19)}$ (n 1092); individuals who had not answered any of the follow-up questionnaires ( $n$ 544); and those who failed to reply to both the 6-year (Q_6) and 8-year (Q_8) follow-up questionnaires ( $n$ 1291), when each MetS criterion was collected. Additionally, we also excluded individuals who had missing information on MetS components at the baseline questionnaire ( $n$ 1039) and those with more than nine items missing in the FFQ ( $n$ 1133). Thus, a total of 6851 participants were included in the final analyses (Fig. 1).

The study was conducted according to the guidelines laid down in the Declaration of Helsinki and all procedures involving human subjects were approved by the Institutional Review Board of the University of Navarra. Voluntary completion of the baseline questionnaire was considered to imply informed consent.
Exposure assessment: snacking between main meals

We evaluated usual snack consumption using the following question included in the baseline questionnaire (Q_0): 'Do you have the habit of snacking between main meals?' The participants were classified into two categories according to their yes or no response.

We did not provide participants a specific definition of what we were meaning when we said 'main meals'. Nevertheless, we feel that, because of specific cultural reasons deeply rooted in Spain, this is not a problem at all in our study. Although the Spanish Society of Community Nutrition recommends eating five times per day and considers the mid-morning and mid-afternoon snacks as part of the regular daily intake ${ }^{(20)}$, in Spain almost $100 \%$ of the general population will always understand without hesitation that 'main meals' include only three meals: breakfast, lunch (the largest meal, eaten at about 14.00 hours) and dinner (usually eaten at about 21.00 hours $)^{(20)}$. As a consequence of this cultural norm, when we evaluated the meaning of the between-meal snacking question among a sub-sample of the cohort ( $n$ 53), $85 \%$ of them considered snacking as an unstructured eating event. All of them defined snacking as small bites of chocolates, candies, savoury snacks, bakery products and processed meat eaten at any irregular time between the main three meals. One hundred per cent of interviewed participants assumed that the main meals were only three: namely breakfast, lunch and dinner. Furthermore, $89 \%$ of them did not include any typical and scheduled mid-morning or mid-afternoon meal in their concept of snacking ${ }^{(7)}$.

Despite the understanding of a sub-sample of our cohort that defined snacking as an irregular consumption of unhealthy products between the main meals ${ }^{(7)}$, in the present study we conducted an exploratory factor analysis to identify snacking patterns among participants who reported snacking between main meals. The rationale for this procedure was that another important aspect to be analysed in the field of snack consumption and chronic diseases is the type of snack chosen. Individuals can choose for snacking healthy products such as fruit and nuts, or unhealthy products like industrial bakery products and sweets.

In this exploratory factor analysis (principal component analysis, with no rotation), we considered thirty-seven potential snacking foods, presented in our 136-item semiquantitative FFQ, as candidate variables to be included in the extracted factors. This FFQ was previously validated in Spain $^{(21)}$. The selection of these thirty-seven items was based on the meaning of 'snack food' among a sub-sample of our cohort $(n 53)^{(7)}$. We retained the first two of the eleven factors with eigenvalue $>1.00(1.02-3.37)$ based on the interpretability and usefulness of the factors. The first factor explained $9 \cdot 1 \%$ of the variance, included ten food items and was characterized by the presence of fruits (orange, apple, strawberry, peach, cherry, fig, melon, 


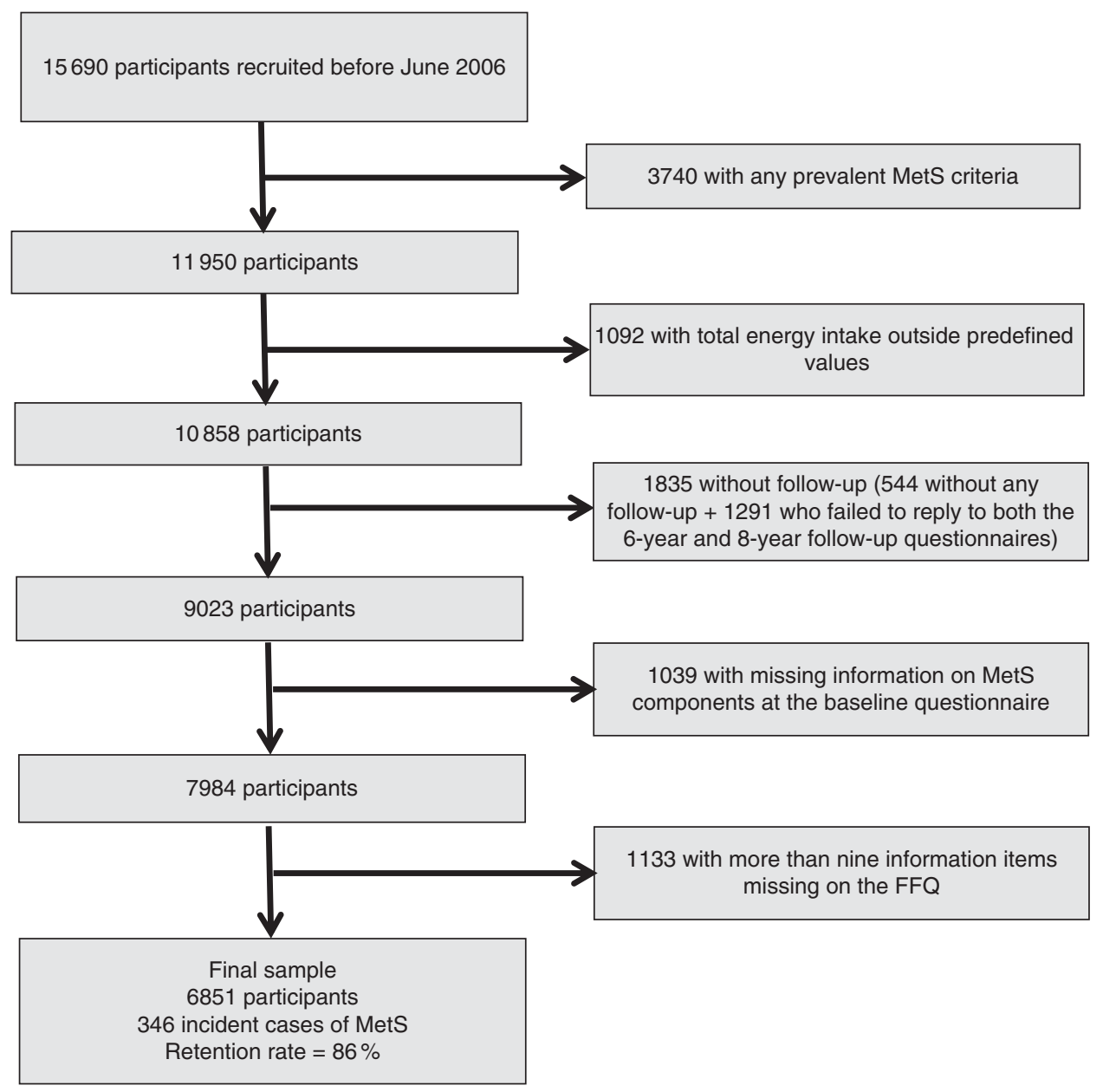

Fig. 1 Flowchart showing selection of participants for the present study (MetS, metabolic syndrome)

watermelon, grape and kiwi); hereinafter termed 'healthy snacking pattern' (factor loadings between 0.37 and 0.70 ). The second factor explained $6.5 \%$ of the variance, included twelve food items and was characterized by the presence of processed meat products, industrial bakery products and other processed foods like French fries, pizza and fruit syrup; hereinafter labelled as 'unhealthy snacking pattern' (factor loadings between 0.30 and 0.46 ). Adherence to the 'healthy snacking pattern' or 'unhealthy snacking pattern' was categorized into quartiles.

\section{Outcome assessment: metabolic syndrome and its components}

MetS was defined according to the International Diabetes Federation and American Heart Association/National Heart, Lung, and Blood Institute harmonizing definition $^{(22)}$. MetS diagnosis required at least three out of the following five criteria: (i) central adiposity $(\geq 94 \mathrm{~cm}$ for men and $\geq 80 \mathrm{~cm}$ for women, cut-off points for European populations); (ii) elevated TAG ( $\geq 150 \mathrm{mg} / \mathrm{dl}$ or presence of pharmacological treatment for hypertriacylglycerolaemia); (iii) reduced HDL-cholesterol $(<40 \mathrm{mg} / \mathrm{dl}$ for men and $<50 \mathrm{mg} / \mathrm{dl}$ for women or presence of pharmacological treatment for reduced HDL-cholesterol); (iv) elevated blood pressure (systolic $\geq 130 \mathrm{mmHg}$ and/or diastolic $\geq 85 \mathrm{mmHg}$ or presence of pharmacological treatment for hypertension in patients with a history of this disease); and (v) impaired glucose metabolism ( $\geq 100 \mathrm{mg}$ / dl or pharmacological treatment for hyperglycaemia).

In Q_6 and Q_8 follow-up questionnaires, self-reported information on these MetS criteria was collected. Waist circumference was measured in a horizontal plane, midway between the inferior margin of the ribs and the superior border of the iliac crest. All participants were sent a tape measure with Q_6 and Q_8 follow-up questionnaires, together with an explanation on how to measure their waist ${ }^{(23)}$.

The validation of the self-reported MetS components was assessed in a specific study within a sub-sample of 287 participants. Significant intra-class correlation coefficients $(P<0.001)$, in the range of 0.5 to 0.9 , were found between self-reported MetS components and their direct assessments by an experienced physician ${ }^{(24)}$. An additional validation study, conducted in another subsample of the SUN Project, found a proportion of confirmed MetS of $91.2 \%$ (95\% CI 80.7, 97.1\%) and non-confirmed MetS of $92.2 \%(95 \%$ CI $85.1,96 \cdot 4 \%)$ in the comparison 
between self-reported diagnosis of MetS and MetS diagnosed by the medical records of the participants ${ }^{(25)}$.

An incident case of MetS was defined when a participant, free of this condition at baseline, met three or more of these components after 6 or 8 years of follow-up (i.e. in either the Q_6 or the Q_8 follow-up questionnaire) ${ }^{(22)}$.

\section{Potential confounding factors}

We considered a wide array of characteristics inquired at the baseline questionnaire as potential confounding factors and adjusted our analysis for them: (i) sociodemographic variables, i.e. sex, age, educational level (technical/nongraduated, graduated, master/doctoral) and marital status (single, married, other: widowed, divorced, cohabiting); (ii) lifestyle and health-related behaviours, i.e. smoking status (never, current, former), physical activity (quartiles of MET $\mathrm{h}$ /week, where MET is metabolic equivalents of task) and time spent viewing television (h/d); and (iii) dietary habits, i.e. consumption of a special diet (vegetarian diet, hypocaloric diet, diet to control lactose intolerance or diet to prevent food allergy), eating away-from-home meals (never to 1-3 times/ month, 1 time/week, $\geq 2$ times/week) and Mediterranean diet adherence $(0-2=\text { low, 3-5 = intermediate, } 6-9=\text { high })^{(26)}$.

Apart from total energy intake $(\mathrm{kJ} / \mathrm{d})$, changes of at least $1 \mathrm{~kg}$ in weight over the last 5 years prior to the study (no change, lost, gained) and baseline BMI $\left(\mathrm{kg} / \mathrm{m}^{2}\right)$ could be intermediate factors in the relationship between snacking consumption and MetS, so we included them in some sensitivity analyses.

Dietary habits were assessed using a 136-item semiquantitative FFQ, previously validated in Spain ${ }^{(21)}$.

Leisure-time physical activity was collected through a validated questionnaire that included information about seventeen activities such as walking, running, cycling, swimming, judo, soccer, skiing or sailing. This questionnaire was previously validated by our group using a triaxial accelerometer as a gold standard. Physical activity during leisure time (estimated as MET h/week) derived from the questionnaire moderately correlated with $\mathrm{kcal} / \mathrm{d}$ assessed through the accelerometer ${ }^{(27)}$.

BMI, defined as weight (in kilograms) divided by height ${ }^{2}$ (in metres), was ascertained at the baseline questionnaire. The validity of self-reported weight was assessed in a sub-sample of the cohort. The mean relative error in self-reported weight was $1.5 \%$. The correlation coefficient between measured and self-reported weight was 0.99 (95\% CI 0.98, 0.99) ${ }^{(28)}$.

\section{Statistical analyses}

To avoid substantial biases and the exclusion of a significant number of participants because they had missing values in the two components of MetS, HDL-cholesterol and TAG levels, at 6-year and/or 8-year follow-up questionnaires and in television watching at the baseline questionnaire, we used a multiple imputation approach to handle missing values. The number of missing values that were imputed with multiple imputations at baseline was
945 for television watching, and at 6-year and 8-year follow-up they were 3103 and 2269 for HDL-cholesterol and 1844 and 1798 for TAG, respectively.

This statistical technique, which tries to overcome the problem that the single imputed values are not actually observed but predicted values, and attributes the most probable value, therefore overestimates the precision and distorts the distribution of the data ${ }^{(29)}$. Instead of a single (most likely) value, twenty values were sampled from an estimated uniform distribution (also taking into account baseline values of sex, age, educational level, marital status, smoking status, alcohol consumption, physical activity, total energy intake, Mediterranean diet adherence and baseline BMI as predictors of the missing value). We imputed their values to 4899 participants who had missing values in HDL-cholesterol and/or TAG and/or time watching television, adding a random term. Hence, twenty data sets with imputed outcomes were created, generating twenty possible values for these variables.

Poisson regression models were fitted to assess the relationship among snacking between main meals and the incidence of MetS. Relative risks (RR) and their 95\% confidence intervals were estimated using as the reference category those participants who did not report snacking between main meals. The results were pooled using standard techniques for multiple imputation that take into account the variation between multiple imputed data sets ${ }^{(29)}$.

A first model included only age and sex as covariates (model 1). We fitted a second model additionally adjusting for educational level, marital status, Mediterranean diet adherence, eating away-from-home meals, smoking, physical activity and television watching (model 2). We also fitted a third model, adjusting for the same variables used in model 2, and adding changes of at least $1 \mathrm{~kg}$ in weight over the last 5 years prior to study inception and baseline BMI (model 3). Finally, we fitted a last model, adjusting for the same variables as in model 3, but adding also total energy intake (model 4).

Then we fitted multivariable Poisson regression models across quartiles of adherence to the 'healthy snacking pattern' and adherence to the 'unhealthy snacking pattern' compared with the non-snacking group, adjusting for the same potential confounding factors used in the models described above.

All analyses were performed with the statistical software package STATA version $12 \cdot 1$ and the statistical significance was set at $5 \%(P<0.05$, based on two-tailed tests $)$.

\section{Results}

We identified 346 new incident cases of MetS (221 in men and 125 in women), among participants initially free of MetS, during a median follow-up of 8.3 years. Thus, the overall cumulative incidence of MetS in this population was $5.0 \%$ (9.5\% for men and $2.8 \%$ for women) and the overall incidence density was $3 \cdot 1 / 1000$ person-years $(6 \cdot 0 / 1000$ personyears for men and 1.5/1000 person-years for women). 
The characteristics of participants according to snacking between main meals are presented in Table 1. Compared with those who did not snack between main meals, participants with this eating habit were more likely to be younger, women, single and have lower years of university education. Moreover, they were more likely to adopt unhealthier lifestyles because they had lower adherence to the Mediterranean dietary pattern, had higher total energy intake, and consumed less fruits and more sweets per day. These participants also had less alcohol consumption, smoked more, were less physically active, watched more television and more frequently gained at least $1 \mathrm{~kg}$ in weight over the last 5 years prior to the study.

Snacking between main meals was associated with a higher risk of MetS development after adjusting for age and sex (RR $=1.46$; $95 \%$ CI 1.19, 1.79; $P<0.001$; Table 2). The strength of this relationship was attenuated, but it remained statistically significant after additionally adjusting for other potential confounding factors (model 2: $\mathrm{RR}=$ 1.44; $95 \%$ CI, 1.18, 1.77; $P<0.001$; Table 2).
We conducted a sensitivity analysis, adjusting our results for potential mediator factors of the relationship between snacking consumption and MetS. Thus, in the third model, we included changes of at least $1 \mathrm{~kg}$ in weight over the last 5 years prior to study inception and baseline BMI as potential confounding factors. The strength of the relationship diminished, but it remained statistically significant (model 3: RR= 1.30; $95 \%$ CI 1.06, 1.60; $P=0 \cdot 012$; Table 2). Finally, additional adjustment for the other potential mediator factor, total energy intake, also slightly decreased the strength of the association but with only a minor change in the statistical significance (model 4: RR $=1.27$; $95 \%$ CI 1.03, 1.57; $P=0.023$; Table 2).

Snacking between main meals did not independently relate to any individual criterion of MetS (Table 2).

We additionally analysed the quality of snacking pattern using the factors obtained in the exploratory factor analysis. Different levels of adherence to a 'healthy snacking pattern' did not differentially exhibit an association with the risk of developing MetS in comparison with the non-snacking group. However, the

Table 1 Baseline characteristics of participants according to snacking between main meals. The SUN Project (Seguimiento Universidad de Navarra; University of Navarra Follow-up), Navarra, Spain, 1999-2013

\begin{tabular}{|c|c|c|c|c|c|}
\hline & \multicolumn{4}{|c|}{ Snacking between main meals } & \multirow[b]{3}{*}{$P$ value } \\
\hline & \multicolumn{2}{|c|}{ No $(n 4480)$} & \multicolumn{2}{|c|}{ Yes $(n 2731)$} & \\
\hline & Mean or $\%$ & SD & Mean or $\%$ & SD & \\
\hline Age (years) & $36 \cdot 2$ & $9 \cdot 8$ & $32 \cdot 7$ & $9 \cdot 1$ & $<0.001 \ddagger$ \\
\hline Sex $(\%)$ & & & & & $<0.001 \S$ \\
\hline Male & 37.9 & - & $26 \cdot 8$ & - & \\
\hline Female & $62 \cdot 1$ & - & 73.2 & - & \\
\hline Educational level (\%) & & & & & $<0.001 \S$ \\
\hline Technical/non graduated & $32 \cdot 3$ & - & $41 \cdot 3$ & - & \\
\hline Graduated & $50 \cdot 2$ & - & 47.5 & - & \\
\hline Master/doctoral & 17.5 & - & $11 \cdot 2$ & - & \\
\hline Marital status (\%) & & & & & $<0.001 \S$ \\
\hline Single & $47 \cdot 3$ & - & 58.7 & - & \\
\hline Married & $48 \cdot 8$ & - & 38.7 & - & \\
\hline Other* & 3.9 & - & $2 \cdot 6$ & - & \\
\hline Mediterranean diet adherence score (\%) & & & & & $<0.001 \S$ \\
\hline $0-2$ points & 13.9 & - & $17 \cdot 1$ & - & \\
\hline $3-5$ points & 59.2 & - & $60 \cdot 1$ & - & \\
\hline $6-9$ points & $26 \cdot 9$ & - & $22 \cdot 8$ & - & \\
\hline Total energy intake $(\mathrm{kJ} / \mathrm{d})$ & 9912 & 2427 & 10360 & 2452 & $<0.001 \neq$ \\
\hline Total energy intake $(\mathrm{kcal} / \mathrm{d})$ & 2369 & 580 & 2476 & 586 & $<0.001 \mp$ \\
\hline Fruits consumption (units/d) & $2 \cdot 3$ & 1.9 & $2 \cdot 2$ & 1.8 & $0.002 \ddagger$ \\
\hline Vegetable consumption (units/d) & 3.0 & 1.5 & 2.9 & 1.4 & $0.107 \ddagger$ \\
\hline Sweets consumption (units/d) $\dagger$ & 1.0 & 0.9 & $1 \cdot 2$ & 0.9 & $<0.001 \ddagger$ \\
\hline Eating away-from-home meals & & & & & $0.585 \S$ \\
\hline Never to $1-3$ times/month & 53.5 & - & 53.6 & - & \\
\hline 1 time/week & $22 \cdot 0$ & - & 21.0 & - & \\
\hline$\geq 2$ times/week & 24.5 & - & $25 \cdot 4$ & - & \\
\hline Alcohol consumption $(\mathrm{g} / \mathrm{d})$ & $6 \cdot 1$ & 8.5 & 5.5 & 8.0 & $0.004 \ddagger$ \\
\hline Current smokers (\%) & $23 \cdot 1$ & - & 24.7 & - & $0.020 \S$ \\
\hline Leisure-time physical activity (MET h/week) & $21 \cdot 8$ & $22 \cdot 6$ & $20 \cdot 0$ & $23 \cdot 1$ & $0.002 \ddagger$ \\
\hline Television watching $(\mathrm{h} / \mathrm{d})$ & 1.6 & 1.3 & 1.8 & 1.4 & $<0.001 \ddagger$ \\
\hline Weight gain at least $1 \mathrm{~kg}$ in the 5 years before (\%) & 47.6 & - & $56 \cdot 4$ & - & $<0.001 \S$ \\
\hline $\mathrm{BMI}\left(\mathrm{kg} / \mathrm{m}^{2}\right)$ & $22 \cdot 6$ & $2 \cdot 7$ & $22 \cdot 7$ & 2.8 & $0.910 \ddagger$ \\
\hline
\end{tabular}

MET, metabolic equivalents of task.

${ }^{*}$ Other = widowed, divorced, cohabiting.

†Sweets consumption = cookies, biscuits, cupcakes, doughnuts, pastries, cakes, chocolates, candies, smashers.

$\ddagger P$ value from Student's $t$ test.

$\S P$ value from Pearson's $x^{2}$ test. 
Table 2 Incidence of metabolic syndrome and its components according to snacking between main meals. The SUN Project (Seguimiento Universidad de Navarra; University of Navarra Follow-up), Navarra, Spain, 1999-2013

\begin{tabular}{|c|c|c|c|c|c|}
\hline & \multicolumn{5}{|c|}{ Snacking between main meals } \\
\hline & \multicolumn{2}{|c|}{ No $(n 4480)$} & \multicolumn{2}{|c|}{ Yes $(n$ 2371) } & \multirow[b]{2}{*}{$P$ value } \\
\hline & $\mathrm{RR}$ & $95 \% \mathrm{Cl}$ & $\mathrm{RR}$ & $95 \% \mathrm{Cl}$ & \\
\hline \multicolumn{6}{|l|}{ Metabolic syndrome } \\
\hline Crude rate ( $n$; per 1000 person-years) & \multicolumn{2}{|c|}{$230 ; 3.2$} & \multicolumn{2}{|c|}{$116 ; 2 \cdot 8$} & \\
\hline Model 1: age- and sex-adjusted & 1.00 & Ref. & 1.46 & $1 \cdot 19,1.79$ & $<0.001$ \\
\hline Model 2: multivariable-adjusted ${ }^{*}$ & 1.00 & Ref. & 1.44 & $1.18,1.77$ & $<0.001$ \\
\hline Model 3: multivariable-adjusted $\dagger$ & 1.00 & Ref. & 1.30 & $1.06,1.60$ & 0.012 \\
\hline Model 4: multivariable-adjustedł & 1.00 & Ref. & $1 \cdot 27$ & $1.03,1.57$ & 0.023 \\
\hline \multicolumn{6}{|l|}{ Components§ } \\
\hline WC, crude rate ( $n$; per 1000 person-years) & \multicolumn{2}{|c|}{$2096 ; 54.3$} & \multicolumn{2}{|c|}{$1177 ; 58.3$} & \\
\hline Model 2: multivariable-adjusted $\ddagger$ & 1.00 & Ref. & 1.02 & $0.95,1.10$ & 0.614 \\
\hline TAG, crude rate ( $n$; per1000 person-years) & \multicolumn{2}{|c|}{$297 ; 4.4$} & \multicolumn{2}{|c|}{$130 ; 3.6$} & \\
\hline Model 2: multivariable-adjusted & 1.00 & Ref. & 1.00 & $0.83,1.19$ & 0.981 \\
\hline HDL-cholesterol, crude rate ( $n$; per 1000 person-years) & \multicolumn{2}{|c|}{$270 ; 2 \cdot 2$} & \multicolumn{2}{|c|}{$133 ; 1.6$} & \\
\hline Model 2: multivariable-adjusted $\ddagger$ & 1.00 & Ref. & 1.01 & $0.89,1.14$ & 0.882 \\
\hline Fasting glucose, crude rate ( $n$; per 1000 person-years) & \multicolumn{2}{|c|}{$925 ; 20.9$} & \multicolumn{2}{|c|}{$420 ; 19.0$} & \\
\hline Model 2: multivariable-adjusted $\ddagger$ & 1.00 & Ref. & 1.04 & $0.92,1.17$ & 0.503 \\
\hline Blood pressure, crude rate ( $n$; per 1000 person-years) & \multicolumn{2}{|c|}{$473 ; 8.7$} & \multicolumn{2}{|c|}{$218 ; 8.2$} & \\
\hline Model 2: multivariable-adjusted $\ddagger$ & 1.00 & Ref. & 1.08 & $0.91,1.27$ & 0.374 \\
\hline
\end{tabular}

RR, relative risk; WC, waist circumference; Ref., reference category.

${ }^{*}$ Model 2: adjusted for age, sex, educational level, marital status, Mediterranean diet adherence, eating away-from-home meals, smoking, physical activity and television watching.

†Model 3: model 2, additionally adjusted for changes at least $1 \mathrm{~kg}$ in weight over the last 5 years prior to the study and baseline BMI.

$\ddagger$ Model 4: model 3 , additionally adjusted for total energy intake.

$\S W C, \geq 80 \mathrm{~cm}$ (women) or $\geq 94 \mathrm{~cm}$ (men); TAG, $\geq 150 \mathrm{mg} / \mathrm{dl}$; HDL-cholesterol, $<50 \mathrm{mg} / \mathrm{dl}$ (women) or $<40 \mathrm{mg} / \mathrm{dl}$ (men); fasting glucose, $\geq 100 \mathrm{mg} / \mathrm{dl} ;$ blood pressure, $\geq 135 / 85 \mathrm{mmHg}$.

Table 3 Incidence of metabolic syndrome according to quartiles of adherence to snack consumption patterns. The SUN Project (Seguimiento Universidad de Navarra; University of Navarra Follow-up), Navarra, Spain, 1999-2013

\begin{tabular}{|c|c|c|c|c|c|c|c|c|c|}
\hline & $\begin{array}{l}\text { Non-snacking } \\
(n \text { 4480) } \\
\end{array}$ & $\begin{array}{l}\text { 1st quartile, } \\
0.01 \text { to } 0.25 \\
\quad(n 599)\end{array}$ & \multicolumn{2}{|c|}{$\begin{array}{l}\text { 2nd quartile, } \\
0.26 \text { to } 0.60 \\
(n 593)\end{array}$} & \multicolumn{2}{|c|}{$\begin{array}{c}\text { 3rd quartile, } \\
0.61 \text { to } 3.57 \\
\text { (n 593) }\end{array}$} & \multicolumn{2}{|c|}{$\begin{array}{l}\text { 4th quartile, } \\
3.58 \text { to } 9.30 \\
\text { (n 586) }\end{array}$} & \multirow[b]{2}{*}{$P$ for trend } \\
\hline & $\mathrm{RR} \quad 95 \% \mathrm{Cl}$ & $\mathrm{RR} \quad 95 \% \mathrm{Cl}$ & $\mathrm{RR}$ & $95 \% \mathrm{Cl}$ & $\mathrm{RR}$ & $95 \% \mathrm{Cl}$ & $\mathrm{RR}$ & $95 \% \mathrm{Cl}$ & \\
\hline \multicolumn{10}{|l|}{ Healthy snacking pattern } \\
\hline Crude rate ( $n$; per 1000 person-years) & $230 ; 3 \cdot 2$ & $25 ; 3 \cdot 2$ & \multicolumn{2}{|c|}{$30 ; 2.7$} & \multicolumn{2}{|c|}{$36 ; 3 \cdot 2$} & \multicolumn{2}{|c|}{$25 ; 2 \cdot 1$} & \\
\hline Model 1: multivariable-adjusted* & 1.00 Ref. & $1.320 .90,1.93$ & 1.32 & $0.93,1.87$ & 1.38 & $0.98,1.95$ & 1.19 & $0.80,1.76$ & 0.057 \\
\hline Model 2: multivariable-adjusted $\dagger$ & 1.00 & $1.320 .90,1.92$ & 1.31 & $0.86,1.93$ & 1.37 & $0.97,1.94$ & 1.19 & $0.80,1.76$ & 0.059 \\
\hline \multirow[t]{3}{*}{ Model 3: multivariable-adjusted } & 1.00 & $1.290 .88,1.89$ & 1.30 & $0.92,1.94$ & 1.35 & $0.95,1.91$ & 1.14 & $0.77,1.69$ & 0.067 \\
\hline & $\begin{array}{l}\text { Non-snacking } \\
\quad(n \text { 4480) }\end{array}$ & $\begin{array}{l}\text { 1st quartile, } \\
0.01 \text { to } 0.28 \\
\quad(n 475)\end{array}$ & \multicolumn{2}{|c|}{$\begin{array}{l}\text { 2nd quartile, } \\
0.29 \text { to } 1.34 \\
\text { (n 560) }\end{array}$} & \multicolumn{2}{|c|}{$\begin{array}{l}\text { 3rd quartile, } \\
1.35 \text { to } 2.59 \\
(n \text { 638) }\end{array}$} & \multicolumn{2}{|c|}{$\begin{array}{l}\text { 4th quartile, } \\
2.60 \text { to } 3.63 \\
\text { (n 698) }\end{array}$} & \\
\hline & $\mathrm{RR} \quad 95 \% \mathrm{Cl}$ & $95 \% \mathrm{Cl}$ & $\mathrm{RR}$ & $95 \% \mathrm{Cl}$ & $\mathrm{RR}$ & $95 \% \mathrm{Cl}$ & $\mathrm{RR}$ & $95 \% \mathrm{Cl}$ & $P$ for trend \\
\hline \multicolumn{10}{|l|}{ Unhealthy snacking pattern } \\
\hline Crude rate ( $n$; per 1000 person-years) & $230 ; 3.2$ & $25 ; 1.7$ & \multicolumn{2}{|c|}{$18 ; 2.4$} & \multicolumn{2}{|c|}{$33 ; 2 \cdot 6$} & \multicolumn{2}{|c|}{$40 ; 4.1$} & \\
\hline Model 1: multivariable-adjusted* & 1.00 & $1.420 .96,2.09$ & 1.06 & $0.69,1.65$ & 1.51 & $1 \cdot 07,2 \cdot 13$ & 1.68 & $1.23,2.29$ & $<0.001$ \\
\hline Model 2: multivariable-adjusted $\dagger$ & 1.00 & $1.210 .82,1.79$ & 0.98 & $0.63,1.51$ & 1.34 & $0.95,1.89$ & 1.56 & $1 \cdot 14,2 \cdot 14$ & 0.003 \\
\hline Model 3: multivariable-adjusted $\neq$ & 1.00 & $1.260 .84,1.87$ & 0.98 & $0.63,1.52$ & 1.32 & $0.94,1.86$ & 1.45 & $1.04,2.03$ & 0.013 \\
\hline
\end{tabular}

$\mathrm{RR}$, relative risk; Ref., reference category.

*Model 1: adjusted for age, sex, educational level, marital status, Mediterranean diet adherence, eating away-from-home meals, alcohol consumption, smoking, physical activity and television watching.

†Model 2: model 1, additionally adjusted for changes at least $1 \mathrm{~kg}$ in weight over the last 5 years prior to the study and baseline BMI.

¥Model 3: model 2, additionally adjusted for total energy intake.

group with the highest adherence to the 'unhealthy snacking pattern' showed a significant association with a higher risk of developing MetS in comparison with the non-snacking group after multivariable adjustment (model $1: \mathrm{RR}=1.51 ; 95 \% \mathrm{CI} 1.07,2.13$ for the third quartile of adherence and $\mathrm{RR}=1 \cdot 68,95 \% \mathrm{CI} 1 \cdot 23,2 \cdot 29$ for the fourth quartile of adherence; model 2: RR=1.56; CI $95 \% 1 \cdot 14$, $2 \cdot 14$ for the fourth quartile of adherence; model $3: \mathrm{RR}=$ 1.45 ; CI $95 \% 1.04,2.03$ for the fourth quartile of adherence; Table 3). 


\section{Discussion}

Results from the SUN Project showed that snacking between main meals was associated with a higher risk for developing MetS. Thus, participants with this eating habit had $44 \%$ higher relative risk to be diagnosed as an incident case of MetS during follow-up. Moreover, the increase in risk became even higher (68\% raised risk) if the snacking pattern was unhealthy. By contrast, there was no association when the snacking pattern was healthy. To the best of our knowledge, the present study is the second one prospectively evaluating the relationship between snacking between main meals and MetS.

The first longitudinal investigation was the Tehran Lipid and Glucose Study, conducted with 1466 adults in Tehran (Iran). Its findings demonstrated that higher consumption of energy-dense snacks was associated with an elevated risk of MetS after 3-years' follow-up ${ }^{(13)}$. As in our study, the authors did not use a specific questionnaire to evaluate snack consumption. Initially, they applied a 168-item FFQ to assess typical food intakes. Then, snacks were determined as foods that were not consumed as part of the main daily meals. These procedures were similar to those that we used to create our first exposure variable, but we consider our assessment of snack consumption more reliable to determine if these foods were eaten between main meals, because we used a specific question to appraise this exposure. Moreover, in the Iranian investigation, unlike our study, they considered only 'unhealthy' foods as snacks. We preferred to classify them into 'healthy' or 'unhealthy' snacks in a second step of our analysis, using exploratory factor analysis.

In an Australian cross-sectional study conducted among 5682 adults, snack consumption was independently associated with a higher prevalence of MetS only among women $^{(14)}$. Here, once again, snack consumption was derived from a full-length FFQ. The exposure variable was created based on a subset of nine food items from the FFQ that represented common snack foods (crackers, sweet biscuits, cakes/pastries, meat pies/pastries/quiches or other, chocolate, flavoured milk, potato chips/crisps, ice cream and hot (fried) chips) according to the Australian Guide to Healthy Eating guidelines. Finally, snack consumption was categorized into two groups based on selfreported daily intake ( $0-3$ servings/d $=$ low; $>3$ servings/ $\mathrm{d}=$ high). This way to assess snack consumption does not differ according to when these foods are eaten, either between main meals or replacing main meals.

We believe that snacking between meals may increase the risk of MetS through increased total energy intake. The participants of our cohort who snacked between main meals had higher total energy intake and had elevated consumption of energy-dense food items such as sweets. Moreover, it has been proposed that snacks between main meals do not generate extra signals of satiety ${ }^{(30)}$. Thus, snacking may lead to a positive energy balance because it exerts a weaker satiety effect than consumption of the same foods during meals and its energy content is not compensated for at the next meal ${ }^{(10)}$. Overweight and obesity, especially abdominal obesity, are the result of a chronic positive energy balance ${ }^{(31)}$ which is also related to other MetS individual criteria such as dyslipidaemia, hyperglycaemia and, consequently, hypertension ${ }^{(31,32)}$.

In this line of thought, the Tehran Lipid and Glucose Study showed that more than $1510 \mathrm{~kJ} / \mathrm{d}$ (361 kcal/d) from energy-dense snacks independently increased the occurrence of $\mathrm{MetS}^{(13)}$.

In general, snack consumers have higher energy intake than non-consumers ${ }^{(13,15,33)}$ and this phenomenon also was observed in our study as described above. Therefore, total energy intake was not introduced in the multivariable adjusted model in the main analysis, since we considered it an intermediate factor in the relationship studied. Nevertheless, even additionally adjusting for total energy intake and other potential intermediate factors, like changes of at least $1 \mathrm{~kg}$ in weight over the last 5 years prior to the study and baseline BMI, the relationship of snacking between main meals and MetS remained statistically significant $(\mathrm{RR}=1 \cdot 27 ; 95 \% \mathrm{CI} 1.03,1 \cdot 57 ; P=0 \cdot 023)$.

However, our findings should be interpreted with caution because we considered as main meals breakfast, lunch and dinner; this is likely to be a historical and sociological definition rather than a physiological classification ${ }^{(10)}$, since to have five meals per day was reported to exert a protective effect against overweight ${ }^{(33)}$, obesity ${ }^{(33)}$, dyslipidaemia ${ }^{(34)}$ and MetS traits ${ }^{(33)}$. In this context, when we evaluated the meaning of the between-meal snacking question among a sub-sample of the cohort, $89 \%$ of participants did not include typical scheduled mid-morning and mid-afternoon meals in their concept of 'snacking' and $85 \%$ of them considered snacking as an unstructured eating event ${ }^{(7)}$.

As mentioned above, the kind of snack choice also could be important to understand the relationship of snacking and chronic diseases. Individuals can choose for snacking healthy products such as fruit and nuts, or unhealthy products like industrial bakery products and sweets. In a study conducted with 5351 subjects from twenty-two centres in Sweden, snacks were positively related to energy intake. Furthermore, sweet and fatty food groups were associated with snacking and contributed considerably to total energy intake ${ }^{(31)}$.

To deal with this question, we conducted additional analyses. Our findings suggested that only when snacking is associated with a higher consumption of nutrient-poor and energy-dense foods ('unhealthy snacking pattern') is it related to a higher risk of MetS. This association also remained statistically significant after adjusting for total energy intake (Table 3, model 3).

A limitation of our study is the self-reported data about snacking between meals. If there is some degree of misclassification, it would probably be non-differential and would bias the association towards the null hypothesis. 
Another limitation is that the snacking patterns were developed with the information collected using the generic full-length FFQ and not a specific questionnaire to ascertain the particular foods only consumed as a snack. Our FFQ was previously validated ${ }^{(21)}$; however, it inquires about foods consumed in all meals and not only as a usual snack between meals. Therefore, our approach is only a proxy to evaluate probable patterns of snacking, not being discarded the risk of misclassification. On the other hand, we consider that by using the full-length FFQ our findings are reinforced, because, by using the larger number of items of the full-length FFQ, we partly overcome the potential limitation of using only a single item (snacking) as the relevant exposure in our study. In addition, FFQ have previously been used to appraise snacks consumption in other studies which have explored the association between this exposure and MetS ${ }^{(13,14)}$.

Moreover, self-reported data were used to assess the MetS components, and this is an acknowledged limitation. However, this information was previously validated in two published sub-studies conducted in our cohort ${ }^{(24,25)}$.

Finally, caution is necessary in extrapolating our results to the general population: because the participants of the SUN Project were volunteers, they could be a group of healthconscious individuals, leading to a self-selection bias ${ }^{(35)}$. On the other hand, the SUN study is composed of university graduates, a population with higher educational level, who are able to provide better quality in their self-reported data. Thus our design is likely to have reduced the degree of misclassification which is inherent to all studies in nutritional epidemiology using self-reported data.

Some other strengths of the present study are its prospective design, the inclusion of a large number of participants, the ability to control for a wide range of potential confounding factors and the long-term follow-up, enabling us to assume a sufficiently large induction period and to avoid or limit reverse causation bias.

\section{Conclusions}

In summary, our findings suggest that the population should be encouraged to reduce snacking between main meals as a preventive approach against the incidence of MetS development. This advice should be especially focused on the reduction of snacks with foods that are energy-dense and poor in micronutrients. Further longitudinal studies in the general population should be conducted to confirm this relationship.

\section{Acknowledgements}

Acknowledgements: The authors thank all members of the SUN Study Group for administrative, technical and material support. They thank the SUN Project participants for their continued cooperation and participation. Financial support: The SUN Project has received funding from the Spanish Ministry of Health and European Regional Development Fund (FEDER) (grant numbers PI10/02993, PI10/02658, PI13/00615, PI14/01668, PI14/01798, PI14/1764, RD06/0045, G03/140) and the Navarra Regional Government (grant numbers 45/2011, 122/2014); and the University of Navarra. A.G. was supported by a FPU fellowship from the Spanish Government. A.M.P. was supported by a postdoctoral fellowship from the Brazilian Government (Coordenação de Aperfeiçoamento de Pessoal de Nivel Superior, CAPES). The funders had no role in the design, analysis or writing of this article. Conflict of interest: None. Authorship: A.M.P. carried out the statistical analysis, drafted the manuscript and gave final approval of the version to be published; A.G. made substantial contributions to analysis and interpretation of the data, was involved in drafting the manuscript, revised it critically for important intellectual content and gave final approval of the version to be published; C.S.-O., I.Z. and R.L.-I. were involved in drafting the manuscript, revised it critically for important intellectual content and gave final approval of the version to be published; M.B.-R. and M.A.M.-G. made substantial contributions to the conception and design of the study and the acquisition, analysis and interpretation of the data, were involved in drafting the manuscript, revised it critically for important intellectual content and gave final approval of the version to be published. Ethics of buman subject participation: All procedures involving human subjects were approved by the Institutional Review Board of the University of Navarra.

\section{References}

1. Kolovou GD, Anagnostopoulou KK, Salpea KD et al. (2007) The prevalence of metabolic syndrome in various populations. Am J Med Sci 333, 362-371.

2. Grundy SM (2008) Metabolic syndrome pandemic. Arterioscler Thromb Vasc Biol 28, 629-636.

3. Fernández-Bergés D, Cabrera de León A, Sanz $\mathrm{H}$ et al. (2012) Metabolic syndrome in Spain: prevalence and coronary risk associated with harmonized definition and WHO proposal. DARIOS study. Rev Esp Cardiol (Engl Ed) 65, 241-248.

4. World Health Organization (2013) World Health Statistics 2013. Geneva: WHO.

5. Yamaoka K \& Tango T (2012) Effects of lifestyle modification on metabolic syndrome: a systematic review and metaanalysis. BMC Med 10, 138 .

6. Andersen CJ \& Fernandez ML (2013) Dietary strategies to reduce metabolic syndrome. Rev Endocr Metab Disord 14, 241-254.

7. Bes-Rastrollo M, Sanchez-Villegas A, Basterra-Gortari FJ et al. (2010) Prospective study of self-reported usual snacking and weight gain in a Mediterranean cohort: the SUN project. Clin Nutr 29, 323-330.

8. Ovaskainen ML, Reinivuo H, Tapanainen H et al. (2006) Snacks as an element of energy intake and food consumption. Eur J Clin Nutr 60, 494-501.

9. De Graaf C (2006) Effects of snacks on energy intake: an evolutionary perspective. Appetite 47, 18-23. 
10. Chapelot D (2011) The role of snacking in energy balance: a biobehavioral approach. $J$ Nutr 141, 158-162.

11. Erlanson-Albertsson C \& Zetterström R (2005) The global obesity epidemic: snacking and obesity may start with free meals during infant feeding. Acta Paediatr 94, 1523-1531.

12. McDonald CM, Baylin A, Arsenault JE et al. (2009) Overweight is more prevalent than stunting and is associated with socioeconomic status, maternal obesity, and a snacking dietary pattern in school children from Bogota, Colombia. J Nutr 139, 370-376.

13. Mirmiran P, Bahadoran Z, Delshad H et al. (2014) Effects of energy-dense nutrient-poor snacks on the incidence of metabolic syndrome: a prospective approach in Tehran Lipid and Glucose Study. Nutrition 30, 538-543.

14. Thorp AA, McNaughton SA, Owen $\mathrm{N}$ et al. (2013) Independent and joint associations of TV viewing time and snack food consumption with the metabolic syndrome and its components; a cross-sectional study in Australian adults. Int J Behav Nutr Phys Act 10, 96.

15. Vergetaki A, Linardakis M, Papadaki A et al. (2011) Presence of metabolic syndrome and cardiovascular risk factors in adolescents and university students in Crete (Greece), according to different levels of snack consumption. Appetite 57, 278-285.

16. Kawada T, Okada K \& Amezawa M (2008) Components of the metabolic syndrome and lifestyle factors in Japanese male workers. Metab Syndr Relat Disord 6, 263-266.

17. Seguí-Gómez M, de la Fuente C, Vázquez Z et al. (2006) Cohort profile: the 'Seguimiento Universidad de Navarra' (SUN) study. Int J Epidemiol 35, 1417-1422.

18. Martinez-Gonzalez MA, Sanchez-Villegas A, De Irala J et al. (2002) Mediterranean diet and stroke: objectives and design of the SUN project. Seguimiento Universidad de Navarra. Nutr Neurosci 5, 65-73.

19. Willett W (1998) Nutritional Epidemiology, 2nd ed. New York: Oxford University Press.

20. Dapcich V, Salvador G, Ribas L et al. (2005) Guide of the Health Diet. Madrid: SENC-Everest.

21. de la Fuente-Arrillaga C, Ruiz ZV, Bes-Rastrollo M et al. (2010) Reproducibility of an FFQ validated in Spain. Public Health Nutr 13, 1364-1372.

22. Alberti KG, Eckel RH, Grundy SM et al. (2009) Harmonizing the metabolic syndrome: a joint interim statement of the International Diabetes Federation Task Force on Epidemiology and Prevention; National Heart, Lung, and Blood Institute; American Heart Association; World Heart Federation; International Atherosclerosis Society; and International Association for the Study of Obesity. Circulation 120, 1640-1645.
23. Klein S, Allison DB, Heymsfield SB et al. (2007) Waist circumference and cardiometabolic risk: a consensus statement from Shaping America's Health: Association for Weight Management and Obesity Prevention; NAASO; The Obesity Society; the American Society for Nutrition; and American Diabetes Association. Am J Clin Nutr 85, $1197-1202$.

24. Fernández-Montero A, Beunza JJ, Bes-Rastrollo $\mathrm{M}$ et al. (2011) Validity of self-reported metabolic syndrome components in a cohort study. Gac Sanit 25, 303-307.

25. Barrio-Lopez MT, Bes-Rastrollo M, Beunza JJ et al. (2011) Validation of metabolic syndrome using medical records in the SUN cohort. BMC Public Health 11, 867.

26. Trichopoulou A, Costacou T, Bamia C et al. (2003) Adherence to a Mediterranean diet and survival in a Greek population. $N$ Engl J Med 348, 2599-2608.

27. Martinez-Gonzalez MA, López-Fontana C, Varo JJ et al. (2005) Validation of the Spanish version of the physical activity questionnaire used in the Nurses' Health Study and Health Professionals' Follow-up Study. Public Health Nutr 8, 920-927.

28. Bes-Rastrollo M, Pérez JR, Sánchez-Villegas A et al. (2005) Validation of the weight and body mass index self-declared by participants in a cohort of university graduates. Rev Esp Obes 3, 352-358.

29. Groenwold RH, Donders AR, Roes KC et al. (2012) Dealing with missing outcome data in randomized trials and observational studies. Am J Epidemiol 175, 210-217.

30. Marmonier C, Chapelot D, Fantino M et al. (2002) Snacks consumed in a nonhungry state have poor satiating efficiency: influence of snack composition on substrate utilization and hunger. Am J Clin Nutr 76, 518-528.

31. Bertéus Forslund H, Torgerson JS, Sjöström L et al. (2005) Snacking frequency in relation to energy intake and food choices in obese men and women compared to a reference population. Int J Obes (Lond) 29, 711-719.

32. Achike FI, To NH, Wang H et al. (2011) Obesity, metabolic syndrome, adipocytes and vascular function: a holistic viewpoint. Clin Exp Pharmacol Physiol 38, 1-10.

33. Jääskeläinen A, Schwab U, Kolehmainen M et al. (2013) Associations of meal frequency and breakfast with obesity and metabolic syndrome traits in adolescents of Northern Finland Birth Cohort 1986. Nutr Metab Cardiovasc Dis 23, 1002-1009.

34. Moschonis G, Mavrogianni C, Karatzi K et al. (2013) Increased physical activity combined with more eating occasions isbeneficial against dyslipidemias in children. The Healthy Growth Study. Eur J Nutr 52, 1135-1144.

35. Gordis L (2014) Epidemiology, 5th ed. Philadelphia, PA: Elsevier Saunders. 